\title{
Knowledge, Awareness And Perceptions Of Females On Clandestine Abortion In Kintampo North Municipality, Ghana
}

\author{
Alhassan Yakubu Alhassan \\ Department of Global Development and Planning, \\ University of Agder, Norway \\ Abdulai Abdul-Rahim \\ Paul Boniface Akaabre \\ Department of Planning, Kwame Nkrumah University of \\ Science and Technology, Kumasi, Ghana.
}

doi: 10.19044/esj.2016.v12n12p95 URL:http://dx.doi.org/10.19044/esj.2016.v12n12p95

\begin{abstract}
Clandestine Abortion will continue to be an integral part of human society as long as people continue to accept and engage in sexual activities without being prepared to give birth. Despite the risks (death and other health complication) involved in clandestine abortion, people continue to engage in the act. The central inquiry is; why do people continue to do clandestine abortions despite its associated risk? Do people have knowledge on abortion concerning its legalities and associated risks? This paper thus seeks to clarify the above questions by examining the knowledge, awareness and perceptions of females on abortion, with focus on clandestine abortion in the Kintampo North Municipality of Ghana. The paper reveals that, though most females have little knowledge on the 1985 abortion law, they are aware of the risks associated with criminal abortion. Despite being aware of the risks, circumstances such as unwanted pregnancies, poverty, desire to pursue education and career goals, and job related issues compel most to abort pregnancies through dangerous means. The paper therefore calls for public education on abortion laws in Ghana to be intensified and possibly, consider shifting the existing paradigms of the abortion law in order to curb clandestine abortions and its associated fatalities.
\end{abstract}

Keywords: Knowledge, Awareness, Perceptions, Abortion, Clandestine or Criminal Abortion 


\section{Introduction}

Procreation or birth is a central component of human life and this can be traced to both Biblical and Quranic origins. This can be seen in the flowing quotations: "God blessed them and said to them, be fruitful and increase in number: fill the earth and subdue it" (Genesis 1:28a). "Wealth and children are an adornment of the life of this world......” (Quran, 18:46). This is not different in the traditional African society as birth comes with pride. Birth is therefore part of every human society and is much valued in many cultures especially in the African context (African Holucost, 2015). However, pregnancy and birth come with many complications ranging from heath, physical, economic and social. These complications have made pregnancy and child bearing dangerous and unsafe for most women in many parts of the world (World Health Organization, 2011). Medical complications during pregnancies and unwanted pregnancy situations lead to abortions (Gutmacher Institute, 2015; Finer and Zolna, 2014). Pregnancies are not always born out of intended acts, thus leading to the concept of unwanted pregnancies. Even in cases where pregnancies are pre-meditated, they are certain times complications that lead people to abortion. Generally, an estimated 40-50 million abortions occur annually in the world; that is, approximately 125,000 abortions per day (WHO in World meters, 2015).

In the views of Mohee and Mohee (2006), abortion is the termination of pregnancy before viability. Viability in medical spheres has pegged at 28 weeks of pregnancy but improvements in modern technologies now appear to be changing this (Hesse and Samba, 2006). Abortion is therefore the termination of pregnancy before its $28^{\text {th }}$ week (WHO, 2012). It includes the termination of pregnancies resulting from natural causes or otherwise. Abortion resulting from natural causes is termed as spontaneous abortion while that resulting from intentional act of human is termed as induced (Worldometers, 2015).

Induced abortions are both legal and illegal depending on the circumstance in which they are undertaken. What constitute legal and illegal abortion varies across countries. Generally, abortion becomes legal when it done within the legal provisions of a country. However, if abortion is done out of the domain or the legal provision, it becomes illegal (Biswas et al, 2012). According to McKechnie (1983), abortion becomes illegal or criminal when it is outside the provisions of law (unlawful). What makes abortion criminal is in terms of the legalities and circumstances under which the act is undertaken. For the purpose of this study, criminal abortion refers to any induced abortion undertaken for any reason outside medical or outside legal provisions and supervision within a given jurisdiction.

The main cause of criminal abortion; particularly in developing countries is unplanned or unwanted pregnancy (Singh et al., 2014), which 
results from the fact that knowledge on contraceptive technology has not reached the point at which sexual intercourse can be handled without becoming pregnant (Gutmacher Institute, 2015; Sedgh and Hussain, 2014; Ahmed et al, 2014: Imegen, 1997). Unplanned pregnancies are mostly unforeseen by parties, which are often deliberate irresponsibility. However, for a woman, the discovery that she is pregnant leads to mixed feelings: surprise, fear of fetal abnormalities, fear of childbirth, and sometimes a distress and probable consequences (Social, Educational, Economic or Emotional) of having a baby. Thus, unplanned pregnancy often results in women pondering over three options: continue the pregnancy and keep the baby; continue the pregnancy and have the baby abandoned or adopted; seek legal or clandestine abortion (illegal abortion), (Jacobs et al, 2014).

In many instances in Sub-Saharan Africa, most women, particularly the teenage opt for clandestine (illegal/criminal) abortions due to legal limitations, limited knowledge and negative cultural values when they are faced with unwanted pregnancies (Vallely et al, 2015: Paltrow, 2015: Thompson et al, 2014). Mohee and Mohee (2006) argues that, when women decide to end an unwanted pregnancy they will often go to extreme length to do so, regardless of whether the procedure is legal, safe or not. They reiterate that as long as unwanted pregnancies occur in societies, abortions will be a fact and part of live. The basic effects of most criminal abortions is medical complications and eventual death of young women (Biswa et al, 2012: Berhan \& Berhan, 2014: Smith, 2013: Baiden et al, 2006). Recent evidence on abortions indicates that the percentage of maternal deaths resulting from unsafe abortion ranges from $8 \%$ to $18 \%$, and the number of abortion-related deaths in 2014 ranged from 22,500 to 44,000 (Say L et al, 2014: Kassebaum et al, 2014) and almost all death from clandestine or criminal abortions were recorded in the developing world (Gutmacher Institute, 2015).

In Ghana, the real concern with this phenomenon is that, despite the alarming statistics and glaring dangers of deaths in clandestine abortions, young women particularly, teenagers still opt for it. Though there is limited existing data on clandestine abortion in many developing countries including Ghana, it is believed that dangerous methods and procedures are used by the pregnant women and some unqualified doctors to do away with the pregnancy (Payne et al, 2013: MOH, 2008: Mohee and Mohee, 2006). According to Payne et al (2013), supported by Oduro \& Otsin (2014), unsafe abortion remains a major public problem in Ghana and a leading cause of maternal deaths in the country. Though there are legal provisions in Ghana to reduce criminal or clandestine abortions, the current law makes enforceability difficult and still places some restrictions to it. This leaves room for untrained personnel to aid females in dangerous abortion activities 
(Rominski et al, 2014: Mohee and Mohee, 2006). This has made it difficult to put an end to criminal abortion act in the country. It is therefore important to explore more avenues that can help reduce criminal or clandestine abortion in the country. It is on this premise that this study seeks to understand the knowledge, awareness and perceptions of females who are mostly victims of the act and issues surrounding it in the country. It also seeks to find out why people keep practicing clandestine abortion despite the risk involved.

The paper uses women in Kintampo North Municipality as the focus and seeks to determine their knowledge, awareness and perceptions on induced criminal abortion in the area. It finds out the proportion of the women who have ever practiced induced criminal abortion, their knowledge on the effects or risks associated with the act, and factors inhibiting the prevention of clandestine abortion in the area. This helps in providing policy directions and reforms towards efforts to combat clandestine (criminal) abortion in Ghana and beyond. The outcome of the study can also aid in designing reproductive health educational tools and programme implementation strategy aiming at reducing clandestine abortion and its associated deaths among young girls in the developing countries; particularly, in sub-Saharan Africa and Ghana per say.

\section{Study setting and approach}

Kintampo North Municipality is one of the local government units in the Brong-Ahafo region of Ghana. It lies between latitudes $8^{\circ} 45^{\prime} \mathrm{N}$ and $7^{\circ} 45^{\prime}$ $\mathrm{N}$ and Longitudes $1^{\circ} 20^{\prime} \mathrm{W}$ and $2^{\circ} 1^{\prime} \mathrm{E}$. Central Gonja Municipal; Bole Municipal to the West; East Gonja Municipal to the North-East, Kintampo South Municipal to the South; and Pru Municipal to the South- East (See Figure 1) bound the area to the north. Kintampo is the administrative capital of the Municipality. It is strategically located at the center of Ghana, with well-known Sceneries; that is, Kintampo waterfall and Fullerfalls, attracting tourists daily from both local and international level.

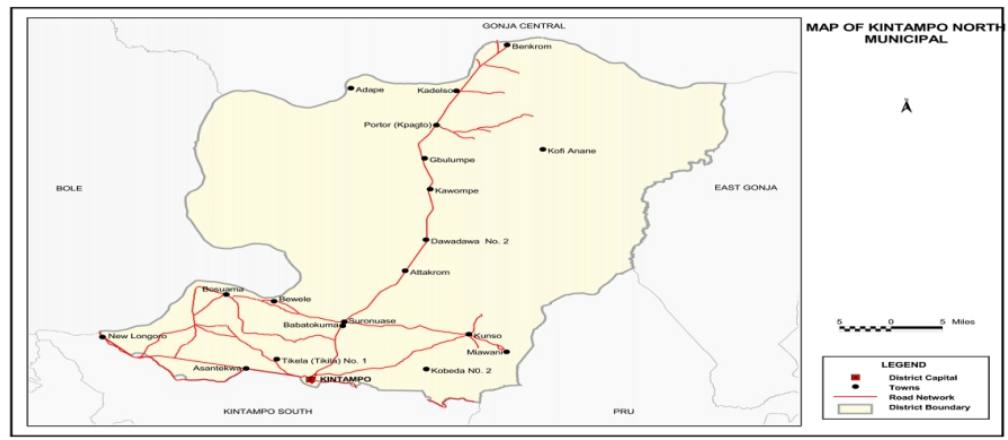

Figure 1 Map of Kintampo Municipality Source: Ghana Statistical Service, 2014 
According to Ghana Statistical Service (2014), as at 2010, the population of Kintampo North Municipality was about 95,480 representing 4.1 percent of the population of Brong Ahafo region of Ghana. The area is female dominated, as they constitute 50.4 percent of the population. This is important for this study as the focus is on female who are the majority in the area. The area has a general youthful population with people less than 15year-old constituting 42\%. About 44 percent of the populations aged 12 years and older are married and 45\% have never married. By ages 25-29 years, more than three quarters of females (64.0\%) are married compared to 33.1\% of males. Generally, the Municipality has a Total Fertility Rate of 3.9, which reflects the national figure of 3.86 as at 2013. Fertility Rate of the Municipality is about 115.1 births per 1000 women aged 15-49 years. This has implications for this study as it shows the nature birth related activities within the municipality (Ghana Statistical Service, 2014).

Considering the nature of the variables involved and what is practical, the study employed the explorative research design. This is because little knowledge about the phenomenon studied. Exploratory research clarifies problems, gathers data and creates initial hypothesis and theories about subjects (Punch, 2004). The study adopted both the quantitative and qualitative research strategy but more attuned to the qualitative strategy due to it being explorative in nature. It seeks to determine the knowledge, awareness and perceptions of females in Kintampo North Municipality on clandestine or criminal abortion. The study population was adolescents and adult aged 15 years and above who are females and classified within the childbearing age, 15-44 years (WHO, 2012). These people stand the risk of getting pregnant or bearing a child and are more likely to be involved in illegal abortion activities. About 250 females randomly selected from ten communities within the Municipality and five institutions to take part in the study. Random sampling, purposive and systematic sampling techniques were employed for this study. The selection of areas for visit was through simple random. Houses to visit and female respondents were selected through systematic sampling. The purposive sampling was used for selecting institutions for interviews. Structured questionnaire containing both written and closed questions were used together with structured interview schedules and interview guides. The questionnaire contained both open ended and close-ended questions.

Both primary and secondary data were used for the study. For the purposes of secondary data, the study reviewed relevant materials on the subject matter already in existence. Some of these sources included books and reports from libraries and the internet where electronic books, journals, reports and web pages where reviewed. Primary data was collected from female adolescents and adults, health institutions and District Assembly. 
Data obtained from the field was analyzed using both qualitative and quantitative techniques. Deductive and Inductive methods were used for the analysis. The type of data collected influenced a more qualitative and little quantitative analyses using to meet the research objectives.

\section{Results and discussion}

This section presents the results and discussions of the data on the perceptions, knowledge and awareness of females on abortion, specifically clandestine abortion in the Kintampo North Municipality.

\section{Characteristics of Respondents}

About $91.3 \%$ of the respondents were within the reproductive age group of 14 - 44 whiles $8.7 \%$ were above the reproductive age of 44 years. About 34\% of respondents within the reproductive age group were teenage adolescents. The involvement of various age groupings was important in coming out with general findings on the knowledge and awareness of females on clandestine abortion in the area. The $91.3 \%$ of women in the reproductive age group (14-44 years) that the study recorded is important as it gives clear view of the awareness level potential clandestine abortion females in the area (WHO, 2010). These people stand the higher risk of involving in criminal abortion, as they are sexually active (Singh et al, 2009). They are also the people who have some sort of independence from their parents and are more likely to involve in sexual activities.

The respondents had strong religious affiliation. About 58.6\% were Christians while 37.3\% were Muslims. The remaining 4.1\% were followers of the African Traditional Religion. The commitment of some respondents to religious values and beliefs affects their decision and likelihood of undergoing criminal abortion. This is because; certain interpretations in these religions have strong beliefs against abortion (Peer Research Centre, 2013). Hence, victims of unplanned pregnancy in the area are likely to opt for clandestine abortion due to religious beliefs and commitment, as decision to abort a fetus is mostly tragic for all concerned, and nowhere more so than in a profoundly religious society like Ghana (Open Saloon, 2010). However, religious affiliation and beliefs can also be a control factor to check sexual behaviors women, which will in turn help reduce unplanned pregnancies among unmarried women.

Generally, most of the respondents had low-level educational background falling between Junior Secondary or Middle School (36.7\%) and Senior Secondary or Vocational School (23.3\%). About 32.6\% had education higher than senior secondary level while $7.4 \%$ never had any form of formal education or had never been in school. Despite $92.6 \%$ of respondents having obtained some level of education, only $59.8 \%$ could read and write the 
English language or the local dialects. The relatively higher proportion of literates in the area will aid the adoption of the English and the local languages, particularly; Twi and Bono in educating people on issues of criminal abortion. This also means that they could be educated through the print and electronic media, and they (59.8\%) can even learn on their own due to their literacy level.

About $47.3 \%$ of the respondents had no children while $52.6 \%$ had either one or more children. Majority of the respondents, 60.4\%, though did not consider themselves as married, had sexual partners with whom they have sexual relationship. They are like consensual marriage since most are sexually active in these relationships. In the case of some, they were sleeping together and doing most things together as marriage couples except that they had not performed the needed rites to recognize them as married couples. They could break the relationship as easily as they wished, with little anticipation of unfaithfulness from any side. The higher proportion (60.4\%) of these forms of unions in the area often results in unplanned pregnancies, hence clandestine abortions. People might be tempted to abort pregnancies in circumstances they break-up with their partners in early periods of the pregnancy. This is more likely because these people are not married and might not be willing to raise children as single parents. Besides, they may want to abort pregnancies to continue satisfying their sexual needs, which they cannot do often during pregnancy periods or at birth.

\section{Sexual Life of Respondents}

About 20.6\% respondents had changed three or more sex partners within the last two years whereas $53.4 \%$ had been with one sex partner since getting into relationships (excluding married couples). About 20\% of the respondents attested that, though they had no permanent sex partners within the last two years, they have had sex within the period. These people appear unstable and could encounter problems when they get pregnant as to who would be responsible. This can therefore tempt them to engage in clandestine abortion.

Surprising, about $27.3 \%$ had their first sexual activity as early as before 15 years. About 45.3\% of the respondents had their first sexual activity with people the respondents mentioned as boyfriend and $17.3 \%$ had their first sex with playmates in their early childhood days. Perhaps, this affirms that sex with boyfriends and girlfriends are common among the teenagers in the area. The high sexual activities among teenagers who are unmarried explain why perpetrators of criminal abortions in Ghana are mostly those in girlfriend/boyfriend relationships (Lithur, 2013). About $32.6 \%$ of the respondents had their first sexual activity with their husbands. This calls into a question the chastity of females in the area since majority of 
them had their first sexual activity even before marriage. Unplanned sexual activities among respondents were $75 \%$. These sexual acts occurred from situations (romance) without prior agreement on that. In these acts, no contraceptives were used as a measure to prevent pregnancies or Sexually Transmitted Diseases. The study also revealed that $38.7 \%$ of respondents who had sex before marriage also had unprotected sex. This confirms the fact that knowledge and willingness to use contraceptives has not reached the desired levels many in the society (Gutmacher Institute, 2015)

The prevalence of early sex and unplanned sex in the area has implications for unwanted pregnancies, which is mostly the main cause of clandestine abortion. Having unprotected sex has a tendency of leading to pregnancy and so do early sex. Pregnancies at early ages of a woman's life may lead to considering possibilities of aborting it. This results from the stigma unmarried young girls with children in the area face. The cultural and religious perception about these people also serves as a threat to keeping unplanned pregnancies.

\section{Induced Criminal Abortion in the Area}

There was general knowledge among the respondents as to what abortion is, most referred to it as the termination of an unwanted pregnancy. However, their knowledge and understanding on abortion was deficient as they limited it to induced abortion taking. Trying to ascertain the statistics on prevalence of clandestine abortion in the area, responded were asked on their involvement in the undertaken act and the responses are show in Figure 2.

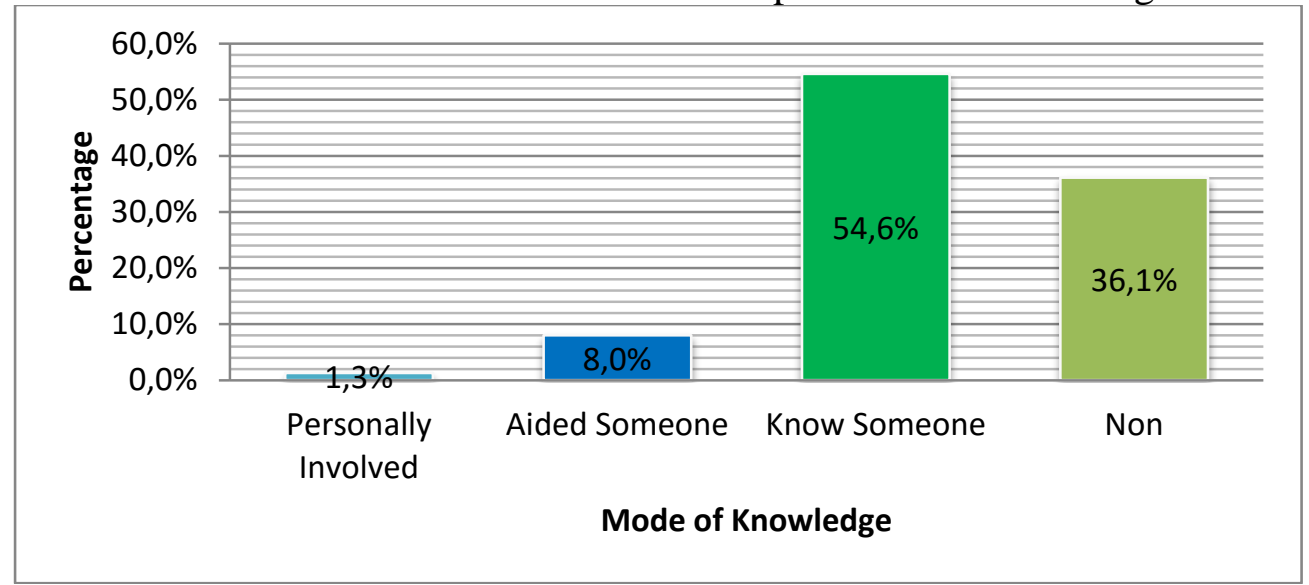

Figure 2: Respondents Engagement or Involvement in Clandestine Abortion

From Figure 2, there was general knowledge and involvement of women in the area in criminal abortion. About $1.3 \%$ of respondents had ever engaged in clandestine abortion in their lives. Also considering involvement, $8 \%$ had ever helped someone do clandestine abortion and 56.8\% know 
someone who has ever committed the act. There were however respondents (11.7\%) who fell into more than one of the categories. About 36.2\% of the respondents were however reluctant in answering this and gave no response. The reluctance of people to answer question regarding this section is a general problem in the Ghanaian society as Ahiadeke (2001) asserts that Ghanaian women participating in community-based surveys on sensitive topics such as pregnancy and abortion are likely to underreport or may be unwilling to provide information.

The survey further revealed that, $53.5 \%$ of those who had ever done clandestine abortion did it before the age of 19 and $19.4 \%$ committed the act after marriage. The remaining were those who committed the act before marriage but not teenagers. These findings support data from Ministry of Health that, a sizable proportion of the demand for abortion services comes from relatively young women, both married and unmarried. The inclusion of non-married women shows that people undertake clandestine abortion at a tender age when they are not married but get pregnant. This is allied to premarital sex and pregnancy, which comes with much stigmatization in the African society. These youngsters therefore choose to abort pregnancies to save them from negative societal view when they find themselves in that situation. In committing this, the study found local Pharmacists (41.3\%) and herbalist $(28.4 \%)$ to be the commonest place where women commit clandestine abortion as shown in Figure 3.

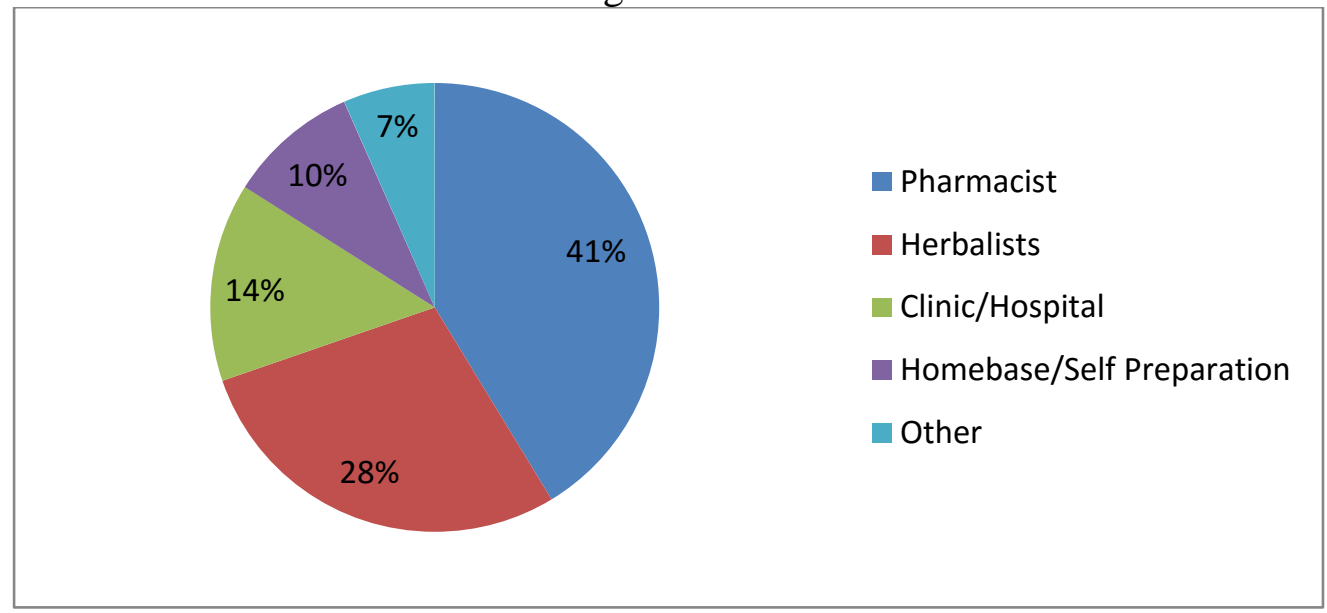

Figure 3: Common Ways of Clandestine Abortion in Kintampo

From Figure 3, the use of pharmacist and herbalist appears to be a place where women think clandestine abortions are easily carried out. This appears to support the findings of Ahiazhe (2001) in the study of induced abortion in southern Ghana, where 65\% of the women said they obtained an abortion from pharmacists and other methods such as self-medication and from "quack doctors". The higher percentage of people choosing herbalists 
and pharmacists as the likely destination for abortion in the area also affirms the findings of lithur (2013) that the commonest method used to conduct illegal abortion in Ghana from 2009 to 2012 was by concoction ("drugs" or "poisonous substance"). This is very hazardous because such agents might not practice any infection prevention technique and might cause sepsis or Pelvic Inflammatory Diseases to their clients. It is also inferred from the data that, the sexual activeness of the women noted earlier has effect on clandestine abortion in the area. The sexual activeness has resulted in many unplanned pregnancies that can result in illegal abortions. The high religious affiliation of the people has done very little in controlling criminal abortion, as its rate is still high despite their religious commitments. Most of the young people had either committed illegal abortion or aided someone to commit the act. They received illegal abortion services from local agents and herbal preparations, which is dangerous to human health and life.

\section{Knowledge on the Effects of Clandestine Abortion}

It was impressive that respondents (71.3\%) know that professional medical Doctors should perform abortion. However, they did not use them but rather adopted different methods despite its risk. The study examined respondents' knowledge on the effects of clandestine or criminal abortion. This was to understand whether it was done without knowing the risk or otherwise. The study revealed that, most respondents were aware of the dangers associated with criminal abortion. Figure 3 shows responses from participants on knowledge regarding the effects of criminal abortion and on people who were suffering or had suffered from some of the effects specified.

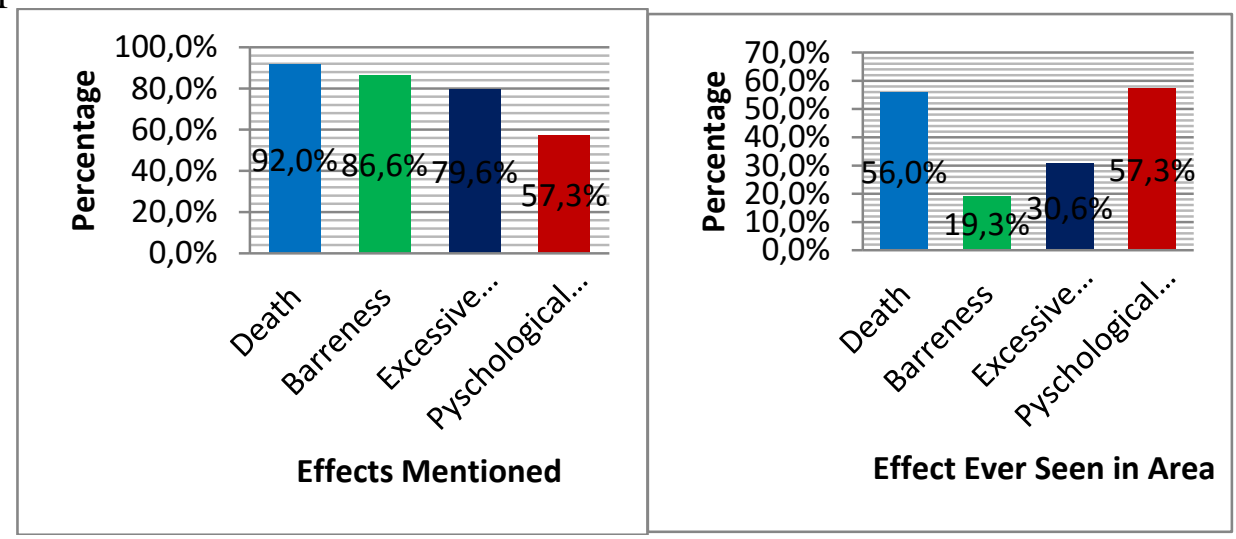

Figure 3: Knowledge on the effects of criminal abortion and on victims of the effects specified.

From Figure 4, about 92.0\% of respondents indicated that abortions; particularly, clandestine abortion can result in deaths confirming literature on 
alarming rate of mortalities resulting from criminal abortions (Biswa et al, 2012: Berhan \& Berhan, 2014: Smith, 2013: Baiden et al, 2006). In addition, $86.6 \%, 79.6 \%$ and $57.3 \%$ respectively mentioned bareness, excessive bleeding and psychological trauma as the major effects associated with abortion. With regard to knowledge or awareness of respondents on the occurrences of these effects in the area, about 56\% indicated that they know someone who died through such act (abortion) in the area. In addition, about $57.3 \%$ revealed that they had ever seen people going through psychological trauma after going through abortion. Besides, $19.3 \%$ and $30.6 \%$ had seen or known someone becoming barren and going through excessive bleeding respectively, after undergoing criminal abortion. This findings show that, the awareness of the effects of criminal or clandestine abortion among women in the area is not just from education, but also from its occurrences within their environment. Women in the area are therefore well aware of the dangers associated with abortion in both abstract and practical terms but do practice it when the need arise. This finding shows that people do criminal abortion not because of ignorance but for other reasons peculiar to their situation. This is due to the fact that majority of women who engage in clandestine abortion are well aware of the dangers associated with it.

\section{Causes of Induced Abortion in the Area}

The study tried to ascertain the major causes of induced abortion or reasons why people practice clandestine abortion in the area. Considering the fact that it was not feasible to get people testifying to undergoing clandestine abortion, the study adopted a perceptional approach to gather this data. Respondents' perceptions on some of the major causes of abortion, particularly clandestine or criminal abortion in the area are depicted in Figure 4.

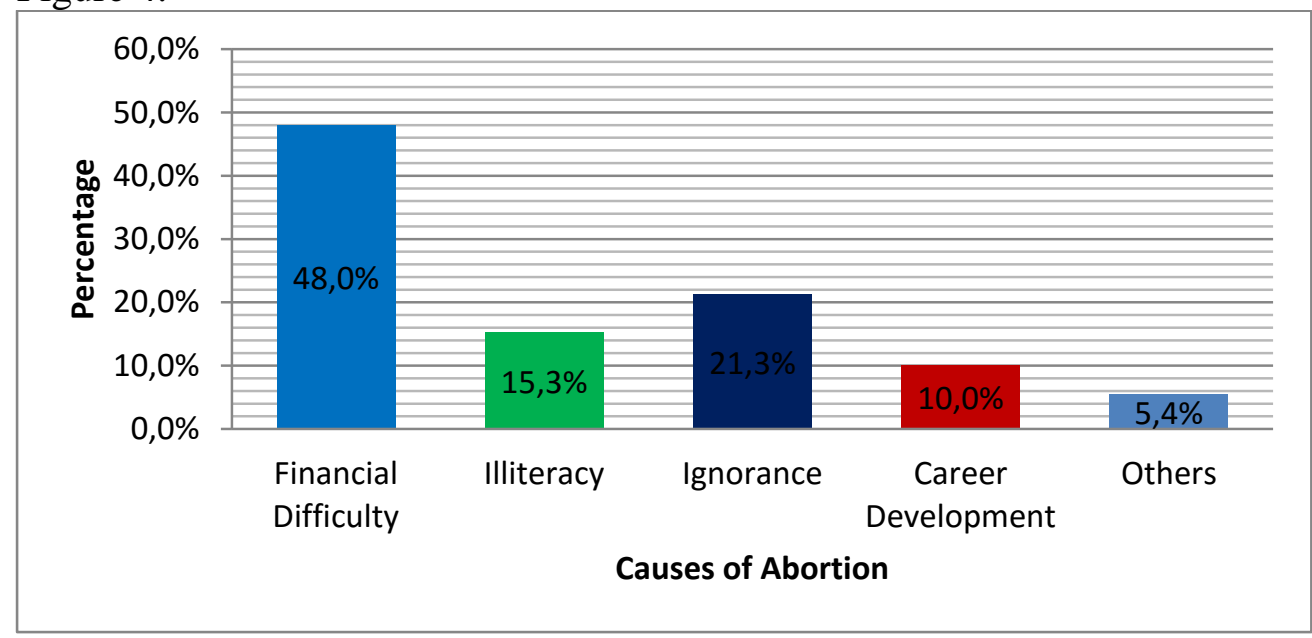

Figure 4: Perception on the Causes of Induced or Clandestine Abortion in Kintampo 
From Figure 5, poverty is the major cause of criminal abortion, with $48 \%$ of respondents citing it. Thus, the inability to take responsibility of pregnancies and take care of the child due to poverty normally results in people aborting pregnancies. About 15.6\%, 21.3\%, $10 \%$ and $5.4 \%$ respectively attributed the cause to illiteracy, ignorance, career development and other issues as the major causes of abortion in the area. Issues mentioned under the others included, social stigma, illegality of certain types of abortion by law, pregnancy during nursing period among others. This data captured only major causes stated by respondents, though some gave more than one. However, poverty still appeared the most attributed cause mentioned by about $98 \%$ of the respondents. Poverty being the dominant cause noted by the respondents confirms the findings by Gamatcher Institute (2014) in the study of abortion in the United States where 69\% women who undertook abortion were economically disadvantaged. Poverty as used by the respondents was limited to income poverty in the area. According to the respondents, inability to afford the cost of abortion with qualified medical personnel often tempt women to use the criminal ways which are mostly less costly. This, they attributed to the low cost of abortion through the use of herbalist and certain pharmaceutical drugs which appeared to be the most common point of abortion for people in the area.

The issue of illiteracy as a cause of criminal abortion is closely associated with ignorance. Respondents attributed both factors as major causes of criminal abortion, however, explanations given for both support the case of ignorance. Respondents therefore viewed ignorance as the consequence of illiteracy. This might however be false in some cases as literates can be ignorant on abortion issues. According to the respondents, societal perceptions on abortion make it difficult to comprehend issues surrounding clandestine abortion. In addition, $60 \%$ of respondents attributed low level of knowledge on laws of abortion as the reason why women opt for clandestine abortions when they genuinely could have sought legal abortions in their case. They think any abortion is illegal in Ghana regardless of the complications and hence, resort to dangerous means to get rid of the pregnancy. This confirms the claim by Lithur (2013) that "despite that the 1985 exemptions clause (rape and incest, risk to pregnant mother, risk to unborn child), which allows for abortions in Ghana, some of the cases were perpetrated even when they qualified for a legal abortion”.

Another important cause the respondents noted was the desire to continue or develop a woman's career. According to some respondents, people in the area sometimes resort to criminal abortion in cases they have pregnancies which might disrupt their careers. One of the respondents who attested to have engaged clandestine abortion remarked that, "I undertook abortion because I just got employed and got pregnant. I had to do that to 
keep my job because giving birth might have cost me my job”. The study noted that, some women in developed countries abort pregnancies to pursue employment or otherwise conserve the limited financial resources of their young family. Similarly, some Ghanaian women seek abortion because they are pursuing an education, have employment obligations or have a young child (Ahiadeke, 2001).

Generally, women in the area appear to blame the occurrence of criminal or clandestine abortion on the society. This was captured in interactions with culprits but was well noted by a medical officer in the area who indicated that,

"The society in which we live is actually the cause. Abortion is not well accepted in the society; women who intend to do that feel bad and are mostly treated like devils when they appear in a special clinic for a better service. In order to rip them off the shame of carrying babies without being married, they turn to try getting rid of babies through life threatening means, with some going to the extent of drinking grinded bottles or resorting to concoctions secretly"

The revelation support the claims made by Akinla and Adadevoh, et al. (1960s) cited in Hesse and Samba (2006) that, abortion in Ghana is a 'medico-social problem. This means that abortion in the country goes beyond the medical spheres as some social factors also drive it.

\section{Recommendation}

To reduce the incidence of clandestine abortion in the country, there is the need to intensify education on abortion concerning its laws. The study revealed that, most females lacked knowledge on laws on abortion in Ghana, hence could not tell the circumstance in which one is legible to seek legal abortion from qualified or professional medical practitioners. They were of the view that abortion is illegal in Ghana. However, per the abortion Law of 1985, not all cases of abortion are illegal in Ghana. The laws indicate that, an abortion is considered legal if it is performed by a qualified medical practitioner or if the pregnancy is the result of rape, incest or 'defilement of a female. It further point out that if continuation of the pregnancy would risk the life of the woman or threaten her physical or mental health; or if there is a substantial risk the child would suffer from a serious physical abnormality or disease, then abortion can be sort legally. Considering the provisions of the law, not all cases of abortion is illegal in the Ghanaian context. However, not many women know the provisions of the law, this is based on the fact about $96 \%$ of the women in the study were ignorant of the provision. Ignorance of this could result in women opting for criminal when they could have sought for legal abortion from qualified medical practitioners. 
The ministry of Gender and Children Affairs, reproductive health Non-Governmental Organizations like Planned Parenthood Association of Ghana, district level agencies like Social Welfare and Community Service Departments should liaise with the National Commission for Civic Education to embark on public education and awareness creation programs on the abortion laws. The programme should focus on the components of the laws and conditions under which one could seek legal abortion in Ghana. It should also take into account the need to eliminate stigmatization on pregnant young women and the perception that when a young lady becomes pregnant or gives birth, her education or professional career or goals has come to an end. This will help reduce the rate of clandestine or criminal abortion in Ghana and it adverse effects.

Besides, as revealed in the survey, the root cause of many criminal abortions is unplanned and unwanted pregnancies. To minimize the rate of clandestine abortion in societies, efforts be directed towards curbing unplanned pregnancies. To achieve this, a collaborative effort from parents, young women, government, and religious leaders, NGOs as well as the Adolescent Reproductive Health Unit of the Ghana Health Service is necessary. Parental upbringing should inculcate sex education as well as providing basic needs of females. It is important for young women to focus on building their careers. Women should try to wait until they get married before having sex with their spouses. The religious leaders have the role to intensify their religious education to maintain sex as a sacred institution for only the married. Intensification on calamity involved in illegal abortions is paramount to deter females from indulging in clandestine abortions in the society. The researchers are of strong conviction that these recommendations would immensely reduce clandestine abortion in the society that adversely affects females.

\section{Conclusion}

Despite the widely held view that unplanned pregnancies lead to abortion or clandestine abortion, other factors like ignorance, poverty, desire to continue career and illiteracy also play key role. Public education and awareness creation on the existing abortion laws should be intensified. This will help parents, girls, NGOs and government institutions to reduce unplanned pregnancies in the country.

Though abortion is an undesired phenomenon in the society, it has now become an integral part of it. Whether society accepts it or not, abortion whether legal or illegal, has become part of it and thus, need significant attention in that regard. In Ghana, most people do clandestine (criminal) abortions and this is because of societal perception and stigmatization on young people who get pregnant in societies. Society will argue and continue 
to argue on whether to legalize all kinds of abortion in the country, or upheld the current laws. Perhaps, most will go against legalizing it and will argue that it is against the doctrines and provisions of their Holy Scriptures of the various religions. There is the need to admit the fact that sex is now an integral part of the society as both married and unmarried; particularly, the youth now practice it. If society and authorities do nothing about that and accepts sex practice among all; particularly, the teenagers and unmarried people, then it must be prepared to give these people the freedom to either keep pregnancies or abort them if they so desire. Perhaps, a new shift in the paradigms of the abortion laws in Ghana needed to avert the effects of criminal or clandestine abortion. Laws that will allow people to seek legal abortion from qualified medical practitioners if they so desire not to keep the pregnancies, regardless of the condition. This will help reduce cases of clandestine abortions in Ghana and its associated risks (deaths and other health complication) females do encounter in trying to abort unplanned pregnancies.

\section{References:}

Ahiadeke, C. (2001). Incidence of Induced Abortion in Southern Ghana. International Family Planning Perspectives, 2(2): 96-101.

Ahmed, A. A., Mohamed, A. A., Guled, I. A., Elamin, H. M., \& Abou-Zeid, A. H. (2014). Knowledge translation in Africa for 21st century integrative biology: The "know-do gap" in family planning with contraceptive use among Somali women. Omics: a journal of integrative biology, 18(11): 696704.

Baiden F, Amponsa-Achiano K, Oduro A, Mensah T, Baiden R, Hodgson A. Unmet need for essential obstetric services in a rural district in northern Ghana: Complications of unsafe abortions remain a major cause of mortality. Pub Hlth, 120 (5):421-426

Berhan, Y., \& Berhan, A. (2014). Causes of maternal mortality in Ethiopia: a significant decline in abortion related death. Ethiopian journal of health sciences, 24, 15-28.

Biswas, H., Das, R. K., \& Talukder, S. I. (2012). Death of a Case of Criminal Abortion by an Unskilled Abortionist. Dinajpur Med Col J, 5(1), 72-5.

Finer, L. B. and Zolna, M. R. (2014). Shifts in intended and unintended pregnancies in the United States, 2001-2008, American Journal of Public Health, 104(S1): S44-S48

Gatmacher Institute (2014). Abortion in the United states. Available online at https://www.guttmacher.org/media/presskits/abortion-US/statsandfacts.html Ghana Statistical Service (2014). 2010 Housing and Population Census, District Analytical Report: Kintampo North Municipality, GSS: Accra-Ghana 
Green, H. T. (1977). Gynecology for Nurses, $2^{\text {nd }}$ edition. Milton Press. New York.

Guttmacher Institute (2015). Unintended Pregnancy in the United States. Accessed on 12/02/2015 at http://www.guttmacher.org/pubs/FB-UnintendedPregnancy-US.html

Hesse, A. and Samba, A, (2006). Comprehensive Reproductive Health in Ghana. Accessed on 12/02/2015 https://www.dawnnet.org/feministresources/sites/default/.../ghana.pdf

Imegen E., (1997). Family Planning Hand Book for Health Professionals: The Sexual and Reproductive Health Approach. International Planned Parenthood Federation, London.

Jacobs, R., Hornsby, N., \& Marais, S. (2014). Unwanted pregnancies in Gauteng and Mpumalanga provinces, South Africa: Examining mortality data on dumped aborted fetuses and babies. SAMJ: South African Medical Journal, 104(12), 864-869.

Kassebaum, N. J., Bertozzi-Villa, A., Coggeshall, M. S., Shackelford, K. A., Steiner, C., Heuton, K. R., ... \& Templin, T. (2014). Global, regional, and national levels and causes of maternal mortality during 1990-2013: a systematic analysis for the Global Burden of Disease Study 2013. The Lancet, 384(9947), 980-1004.

Lithur, N. O. (2013) Reported Cases of Illegal Abortions in Ghana 20092012. A paper presented by the Human Rights Advocacy Centre. AccraGhana.

McKechnie, J.L. (1983). Webster's New Twentieth Century Dictionary Second Edition, Simon \& Schuster, New York -USA

Morhee, R. A. S. and Morhee E.S. K. (2006). Overview of the Law and Availability of Abortion Services in Ghana, Ghana Medical Journal. 40(3): 80-86

Oduro, G. Y., \& Otsin, M. N. A. (2014). “Abortion-It Is My Own Body”: Women's Narratives About Influences on Their Abortion Decisions in Ghana. Health care for women international, 35(7-9), 918-936.

Open Saloon (2010). Abortion in Ghana - Where ignorance of the law can be fatal. Accessed on 20/12/2015 http://open.salon.com/blog/judy_mandelbaum/

Paltrow, L. M. (2015). How Indiana is making it possible to jail women for having abortions. The Public Eye. Available at http://www.politicalresearch.org/2015/03/29/how-indiana-is-making-itpossible-to-jail-women-for-having-abortions/

Payne, C. M., Debbink, M. P., Steele, E. A., Buck, C. T., Martin, L. A., Hassinger, J. A., \& Harris, L. H. (2013). Why women are dying from unsafe abortion: narratives of Ghanaian abortion providers. African Journal of Reproductive Health, 17(2), 118-128. 
Pew Research Centre (2013). Religious Groups' Official Positions on Abortion. Accessed on 20/12/2015 http://www.pewforum.org/2013/01/16/religious-groups-official-positions-onabortion/

Punch, K. F. (2005). Introduction to Social Research. Quantitative and Qualitative Approaches (2nd ed.). London: Sage.

Rominski, S. D., Gupta, M., Aborigo, R., Adongo, P., Engman, C., Hodgson, A., \& Moyer, C. (2014). Female autonomy and reported abortion-seeking in Ghana, West Africa. International Journal of Gynecology \& Obstetrics, 126(3), 217-222.

Say, L., Chou, D., Gemmill, A., Tunçalp, Ö., Moller, A., Daniels, J., Gülmezoglu, A. M., Temmerman, M., and Alkema, L. (2014). Global causes of maternal death: a WHO systematic analysis, The Lancet Global Health, 2(6): e323-e333.

Sedgh G and Hussain R. (2014). Reasons for contraceptive nonuse among women having unmet need for contraception in developing countries, Studies in Family Planning, 45(2):151-169.

Singh S et al., (2014). Adding It Up: The Costs and Benefits of Investing in Sexual and Reproductive Health 2014, Guttmacher Institute: New YorkUSA

Smith, S. S. (2013). Reproductive health and the question of abortion in Botswana: a review. African journal of reproductive health, 17(4): 26-34.

Thompson, J., Undie, C. C., \& Askew, I. (2014). Access to emergency contraception and safe abortion services for survivors of rape: a review of policies, programmes and country experiences in sub-Saharan Africa. Accessed on 12/02/2016 at r4d.dfid.gov.uk/Output/197400/

Vallely, L. M., Homiehombo, P., Kelly-Hanku, A., \& Whittaker, A. (2015). Unsafe abortion requiring hospital admission in the Eastern Highlands of Papua New Guinea-a descriptive study of women's and health care workers' experiences. Reproductive health, 12(1), 22.

WHO (2010). What health-care providers say on providing abortion care in Cape Town, South Africa: findings from a qualitative study. Social science research policy brief. Accessed on 2012/2015 at Available at whqlibdoc.who.int/hq/2010/WHO_RHR_HRP_10.18_eng.pdf

WHO (2011). Unsafe abortion: global and regional estimates of the incidence of unsafe abortion and associated mortality in 2008. Sixth edition. Accessed on 1/01/2015 at http://www.who.int/reproductivehealth/publications/unsafe_abortion/978924 1501118/en/

WHO (2012). Safe and unsafe induced abortion - Global and regional levels in 2008, and trends during 1995-2008. Information sheet. Accessed on 
$1 / 01 / 2015$

apps.who.int/iris/bitstream/10665/75174/1/WHO_RHR_12.02_eng.pdf

at

Worldometers (2015). Abortions worldwide this year. Accessed on 20/02/2016 at http://www.worldometers.info/abortions/ 